\title{
Comparison of Chemical Compositions of Maitake (Grifola frondosa (Fr.) S. F. Gray) Cultivated on Logs and Sawdust Substrate
}

\author{
Takeo TABATA, ${ }^{1}$ Yoshio YAMASAKI ${ }^{1}$ and Tetsuya OGURA ${ }^{2}$ \\ ${ }^{1}$ Kobe Women's University Seto Junior College, 721 Kannonji, Seto-cho, Akaiwa-gun, Okayama 709-0863, Japan \\ ${ }^{2}$ Universidad Autonoma de Guadalajara, Departamento de Quimica, CEN, Apdo Postal 1-440, Guadalajara, Jalisco, Mexico
}

Received May 21, 2003; Accepted October 2, 2003

\begin{abstract}
Maitake mushroom was cultivated on logs and in sawdust substrate. Comparisons of proximate compositions, content of free amino acid, $5^{\prime}$-nucleotides and vitamin $D_{2}$ were conducted. Effects of the log and sawdust substrate compositions on the mushroom composition were also examined. Protein and ash in sawdust mushroom were significantly higher than that in the log mushroom. Protein content of fruit body cultivated on sawdust substrate was closely related to the content of the substrate. This fact well explained the difference in protein and ash contents between mushroom cultivated on log or sawdust substrate. Free amino acid content as MSG-like and sweetness components, and $5^{\prime}$-GMP were significantly higher in log mushroom. The content of vitamin $D_{2}$ was appreciably higher in sawdust mushroom than that in log mushroom.
\end{abstract}

Keywords: Maitake mushroom, log, sawdust substrate, proximate composition, free amino acid, $5^{\prime}$-GMP, vitamin $\mathrm{D}_{2}$

Maitake mushroom, G. frondosa (Fr.) S. F. Gray, is a white-rot fungus found in the wild on dead stumps of broad leaf trees such as oak (Quercus mongolica) and chestnut (Castanea crenata) (Imazeki \& Hongo, 1985). Almost 40,000 metric tons of the cultivated mushroom was consumed in 1999 in Japan being the fourth largest production (Ohashi, 2000).

Numerous investigations have been reported on the components of G. frondosa (Yokokawa 1980; Kurasawa et al., 1982; Sato et al., 1985; Takeuchi et al., 1985; Muratsubaki et al., 1986; Kawai et al., 1990; Sekizawa et al., 1992; Yoshida et al., 1996; Ohnishi et al., 1996; Shindo et al., 1999). It is interesting that consumption of the mushroom is a way to assimilate antitumor (Ohno et al., 1985; Zhuang et al., 1994; Kubo et al., 1994), antidiabetes and antihyperliposis (Kubo et al., 1994, 1997), blood pressure and body weight depressive substances (Ohtsuru et al., 1999). Furthermore, Seguchi et al. (2001) added G. frondosa powder to improve the quality of bread.

G. frondosa is mainly cultivated on the sawdust of broad leaf trees supplementing the source of nutrients such as rice or wheat bran. This method makes it possible to cultivate on a large scale and to harvest all year round. However, it has been said that sawdust $G$. frondosa is less tasty than $\log G$. frondosa. A few investigations have been reported on the comparison of chemical compositions of mushroom cultivated on logs and sawdust substrates (Aoyagi et al., 1993; Kawai et al., 1994; Sasaki et al., 1995). However, no study is found on a comparison of the taste components between the sawdust mushroom and log mushroom.

Previously, we compared the chemical and free amino acid composition of $P$. nameko cultivated on $\log$ and in sawdust substrate beds (Yamasaki \& Tabata, 2002).

In this paper, we compared the proximate compositions, free amino acid, 5'-nucleotides, vitamin $\mathrm{D}_{2}$ of $G$. frondosa cultivated

E-mail: t.tabata@alpha.ocn.ne.jp on logs and sawdust substrates and their relation to the composition of the substrates.

\section{Materials and Methods}

The strain of $G$. frondosa was purchased from Onuki Kinjin Co., Utsunomiya-shi. The mushroom was cultivated at the farm of the Kobe Women's University Biotechnology Institute.

Sawdust-based cultivation of G. frondosa Hardwood sawdust, Quercus acutissima Carr., was made with a wood mill. The substrate was composed of $750 \mathrm{~g}$ (fresh weight) of hardwood sawdust, and $250 \mathrm{~g}$ of rice bran. Its moisture content was made up to $70 \%$ by the addition of tap water. Thereafter polypropylene bottles (approximate capacity: $900 \mathrm{ml}$ ) were filled and a cavity was made in the center for solid spawn inoculation, which was then sealed with a cap. Bottles with substrate were sterilized at $121^{\circ} \mathrm{C}$ (1.1 atm) for $2 \mathrm{~h}$, and then allowed to cool overnight. Each substrate was inoculated with $10 \mathrm{~g}$ of solid sawdust spawn of $G$. frondosa. The bottles were incubated at $23^{\circ} \mathrm{C}$ in the dark.

When the spawn had grown well throughout the medium, the cultures were subjected to the Kinkaki treatment (scratching away and removal of surface mycelia in the culture bottle). Cultures were then transferred to culture rooms maintained at $15^{\circ} \mathrm{C}$ to initiate fruiting body formation. In the final step relative humidity was maintained at $75-80 \%$ to grow the fruiting bodies.

Cultivation of $G$. frondosa using felled logs In March 1999 logs of Quercus acutissima Carr., a broad leaf tree, which had been cut in the fall of the previous year were cut into $15 \mathrm{~cm}$ lengths. Two segments were superposed to use as a substrate for the cultivation. Solid sawdust spawn of $G$. frondosa cultured on sawdust medium were inserted between paired segments. The pairs were piled up outside of a building, covered with PVC sheets, and left until the first of July (Karibuse). Attention was given to attaining a good air flow through the piles during the period of Karibuse. When the log segments were sufficiently per- 
meated with the spawn, they were transferred to a Fusekomi. The paired segments were divided into two, and the sides that were permeated with the mycelium was embedded in soil. Each culture bed was occasionally sprinkled with water to keep it moist until the fruiting of $G$. frondosa took place. In the fall one year after the mushroom seeds were inoculated, the fruiting bodies of the mushroom were developed on almost the entire bed-log. Fruiting bodies harvested from the log or the sawdust cultivation were dried in a forced air-oven at $50-60^{\circ} \mathrm{C}$ for $70 \mathrm{~h}$. Dried samples were ground in a stainless steel mill to obtain a homogeneous sample.

Proximate composition The moisture, protein, fat and ash were determined according to the conventional method (Sugahara, 1995).

The nitrogen-protein conversion factor of 6.25 and 4.33 was employed to calculate the protein contents for the substrate bed and mushroom, respectively. The use of common factor 6.25 in protein analysis for mushroom containing more nonprotein may result in overestimation of the protein content. Therefore, the later value of 4.33 was derived from analytical total nitrogen and amino acid residue data of $G$. frondosa (Fujihara et al., 1995). The amount of carbohydrate was estimated by subtracting the amount of protein, fat and ash from $100 \%$.

Free amino acid assay Dried mushroom powder (1000 $\mathrm{mg}$ ) was shaken with $25 \mathrm{ml}$ of $10 \%$ (w/v) sulfosalicylic acid (Wako Pure Chemical Industries Co., Osaka) for $20 \mathrm{~min}$ at ambient temperature and filtered through Whatman No. 4 filter paper. The filtrate was adjusted to $\mathrm{pH} 2.2$ with $3 \mathrm{~N} \mathrm{NaOH}$ and made up to $100 \mathrm{ml}$ with sodium citrate buffer (Wako reagent as described above). One milliliter of that extract was diluted to $5 \mathrm{ml}$ and filtered through a Millipore LH nonsterile filter (pore size 0.45 $\mu \mathrm{m})$. The diluted filtrate was mixed with $o$-phthalaldehyde reagent (Wako) in an Eppendorf tube, shaken to facilitate derivatization, and then immediately injected onto a high-performance liquid chromatograph (HPLC). A Shimadzu LC-6A equipped with fluorescence detector, with fluorescence excitation at 348 $\mathrm{nm}$ and emission at $450 \mathrm{~nm}$, and a Shim-pack ISC-07/S $1504 \mathrm{Na}$ column (Shimadzu) were used. Each amino acid was quantified by a calibration curve of the authentic amino acid.

5'-Nucleotide assay 5'-Nucleotides were extracted and analyzed as described by Kiribuchi and Kawashima (1992). Dried mushroom powder $(1000 \mathrm{mg})$ was suspended in $50 \mathrm{ml}$ of deionized water. It was treated for $25 \mathrm{~min}$ : 4 min until the extract reached a boil, $15 \mathrm{~min}$ of boiling, and $6 \mathrm{~min}$ of cooling. The extract was adjusted to $50 \mathrm{ml}$ by adding deionized water, then was centrifuged at $3000 \mathrm{rpm}$ for $10 \mathrm{~min}$. The supernatant was filtered

Table 1. Proximate composition in the $\log$ and sawdust media.

\begin{tabular}{lcc}
\hline & \multicolumn{2}{c}{ Content $(\%)^{a)}$} \\
\cline { 2 - 3 } & Sawdust substrate ${ }^{b)}$ & Log substrate \\
\hline Moisture & $68.40 \pm 0.87$ & $47.60 \pm 0.22$ \\
Protein ${ }^{c}$ & $1.66 \pm 0.04(5.25)$ & $0.86 \pm 0.01(1.64)$ \\
Fat & $2.13 \pm 0.10(6.74)$ & $0.44 \pm 0.08(0.84)$ \\
Ash & $1.15 \pm 0.08(3.64)$ & $0.81 \pm 0.04(1.55)$ \\
Carbohydrate & $26.66 \pm 0.27(84.37)$ & $50.29 \pm 0.09(95.97)$ \\
\hline${ }^{a)}$ Mean \pm standard deviation $(n=3)$. Numbers in parenthesis indicate the per- \\
centage on a dry basis. ${ }^{b)}$ The sawdust medium was composed of sawdust \\
from Quercus acutissima Carr. and rice bran $(3: 1 \mathrm{w} / \mathrm{w}) .{ }^{c}$ The nitrogen fac- \\
tor used for protein calculation was 6.25.
\end{tabular}

using $0.45 \mu \mathrm{m}$ LH nonsterile filter (Millipore) prior to injection onto the HPLC.

The HPLC system was the same as for amino acid assay except for a UV detector and a Shim-pack CLC-ODS column ( $5 \times 150 \mathrm{~mm}$, Shimadzu). The temperature of the column was $40^{\circ} \mathrm{C}$, the mobile phase was $24 \mathrm{mM}$ 2-diethylaminoethanol-16 $\mathrm{mM}$ citric acid, the flow rate was $0.9 \mathrm{ml} / \mathrm{min}$ and $\mathrm{UV}$ detection at $250 \mathrm{~nm}$. Each $5^{\prime}$-nucleotide was quantified by the calibration curve of the authentic $5^{\prime}$-nucleotide.

Vitamin $D_{2}$ assay The determination of vitamin $\mathrm{D}_{2}$ in the fruiting bodies was carried out by the method of Kawazoe and Yuasa (1995). About $2 \mathrm{~g}$ of sample was accurately weighed and saponified. The extracted unsaponifiable matter was applied to the HPLC to determine vitamin $\mathrm{D}_{2}$. The chromatography was performed using a TOSOH ODS-80, TM column (reversedphase type, $4.6 \times 150 \mathrm{~mm}$ i.d.) with methanol and water $(95 / 5 \mathrm{v} /$ v) as the mobile phase. The flow rate was $0.8 \mathrm{ml} / \mathrm{min}$, and the UV detector was set at $265 \mathrm{~nm}$. The content of vitamin $\mathrm{D}_{2}$ in the fruit body was determined using pure vitamin $\mathrm{D}_{2}$ (Wako).

\section{Results and Discussion}

The proximate compositions in these substrates are shown in Table 1. Protein, fat and ash were significantly higher in sawdust substrate than those in logs. On the contrary, carbohydrate was notably higher in logs. The carbohydrate content of the sawdust medium was reduced to less than that of the log by the supplementation of the rice bran which contained less carbohydrate than the log. Additionally, the high protein, fat, and ash content might be the result of the rice bran which was added to the sawdust.

The proximate composition of fruiting bodies of $G$. frondosa is shown in Table 2. It has been reported that the fruiting bodies contain $4.4-6.5 \%$ ash, $1.5-4.5 \%$ fat, $13.1-18.4 \%$ protein and $70.6-80.8 \%$ carbohydrate based on dry weight (the originally reported values in protein and carbohydrate were reevaluated using nitrogen-to-protein conversion factor 4.33) (Kurasawa et al., 1982; Muratsubaki et al., 1986). The protein and ash contents in sawdust mushroom were slightly above this range, whereas that in log mushroom was within this range.

Ash and protein in the sawdust mushroom were higher than those in the log mushroom but carbohydrate was higher in the log mushroom. Therefore, the observed high carbohydrate content in log mushroom is partly responsible for the lower protein, for it was estimated by subtracting the protein and others from the sample. Our analytical data are in good agreement with the results of Shiitake (Lentinus edodes) by Aoyagi et al. (1993) that sawdust mushroom contained more nitrogen and ash than log

Table 2. Proximate composition in the sawdust mushroom and log mushroom.

\begin{tabular}{|c|c|c|}
\hline & \multicolumn{2}{|c|}{ Content $(\%)^{a)}$} \\
\hline & Sawdust mushroom & Log mushroom \\
\hline Moisture & $90.41 \pm 1.09$ & $92.47 \pm 0.87$ \\
\hline Protein ${ }^{b)}$ & $1.78 \pm 0.05(18.56)$ & $1.02 \pm 0.02(13.55)$ \\
\hline Fat & $0.23 \pm 0.09(2.40)$ & $0.11 \pm 0.05(1.46)$ \\
\hline Ash & $0.68 \pm 0.06(7.08)$ & $0.34 \pm 0.05(4.52)$ \\
\hline Carbohydrate & $6.90 \pm 0.32(71.95)$ & $6.06 \pm 0.25(80.47)$ \\
\hline
\end{tabular}

a) Refer to Table 1 .

b) The nitrogen factor used for protein calculation was 4.33 . 
Table 3. Content of free amino acids in the sawdust mushroom and log mushroom.

\begin{tabular}{lcc}
\hline \multirow{2}{*}{ Amino acid } & \multicolumn{2}{c}{ Content $(\mathrm{mg} / \mathrm{g}, \text { dry weight })^{a)}$} \\
\cline { 2 - 3 } & Sawdust mushroom & Log mushroom \\
\hline L-alanine & $2.15 \pm 0.06$ & $3.13 \pm 0.08$ \\
L-arginine & $3.02 \pm 0.06$ & $3.21 \pm 0.09$ \\
L-aspartic acid & $1.61 \pm 0.03$ & $1.25 \pm 0.04$ \\
L-glutamic acid & $8.01 \pm 0.08$ & $9.10 \pm 0.12$ \\
Glycine & $1.53 \pm 0.04$ & $1.53 \pm 0.03$ \\
L-histidine & $1.53 \pm 0.02$ & $0.94 \pm 0.03$ \\
L-isoleucine & $0.12 \pm 0.007$ & $0.12 \pm 0.007$ \\
L-leucine & $0.05 \pm 0.007$ & $0.09 \pm 0.007$ \\
L-lysine & $1.56 \pm 0.06$ & $1.28 \pm 0.05$ \\
L-proline & $2.35 \pm 0.04$ & $2.55 \pm 0.03$ \\
L-phenylalanine & $0.26 \pm 0.01$ & $0.28 \pm 0.01$ \\
L-serine & $2.91 \pm 0.11$ & $2.82 \pm 0.05$ \\
L-threonine & $1.43 \pm 0.03$ & $1.44 \pm 0.04$ \\
L-tyrosine & $1.77 \pm 0.02$ & $0.73 \pm 0.02$ \\
L-valine & $0.96 \pm 0.01$ & $0.91 \pm 0.01$ \\
Total & $29.26 \pm 0.58$ & $29.38 \pm 0.61$ \\
\hline
\end{tabular}

${ }^{a)}$ Mean \pm standard deviation $(n=3)$.

Table 4. Taste characteristics of free amino acids in the sawdust mushroom and $\log$ mushroom.

\begin{tabular}{|c|c|c|c|c|}
\hline \multirow{2}{*}{$\begin{array}{l}\text { Taste } \\
\text { characteristic }\end{array}$} & \multicolumn{4}{|c|}{ Content (mg/g, dry weight $)^{a)}$} \\
\hline & Sawdust mushroom & Ratio (\%) & Log mushroom & Ratio $(\%)$ \\
\hline Bitterness $^{b)}$ & $5.94 \pm 0.11$ & 20.3 & $5.55 \pm 0.15$ & 18.9 \\
\hline MSG-like $^{c)}$ & $9.62 \pm 0.11$ & 32.9 & $10.35 \pm 0.16$ & 35.2 \\
\hline Sweetness $^{d)}$ & $10.37 \pm 0.28$ & 35.4 & $11.47 \pm 0.23$ & 39.0 \\
\hline Tasteless $^{e)}$ & $3.33 \pm 0.08$ & 11.4 & $2.01 \pm 0.07$ & 6.9 \\
\hline Total & $29.26 \pm 0.58$ & 100 & $29.38 \pm 0.61$ & 100 \\
\hline
\end{tabular}

a) Mean \pm standard deviation $(n=3)$.

b) $\mathrm{Val}+\mathrm{Ile}+\mathrm{Leu}+\mathrm{Phe}+\mathrm{His}+$ Arg. ${ }^{c}$ Monosodium glutamate-like, Asp+Glu.

${ }^{d)} \mathrm{Thr}+\mathrm{Ser}+$ Pro + Gly + Ala. ${ }^{e} \mathrm{Tyr}+$ Lys.

mushroom, whereas the content of carbohydrate was lower than $\log$ mushroom.

Kawai et al. (1994) reported that the protein content of fruiting bodies of Hiratake (Pleurotus ostreatus) was significantly related to the nitrogen content of the sawdust medium. However, Sasaki et al. (1995) reported that the nitrogen content of Bunashimeji (Hypsizigus marmoreus), Nameko (Pholiota nameko) and Enokitake (Flammulina velutipes) was not significantly related to that of the sawdust substrate.

Table 3 shows that there is no significant difference in total amino acid contents between the sawdust mushroom and log mushroom; however, log mushroom contained more glutamic acid and alanine than sawdust mushroom. On the other hand, histidine and tyrosine were significantly higher in sawdust mushroom than in log mushroom. The two mushroom types had the same degree of the essential amino acids isoleucine, leucine, lysine, phenylalanine, threonine and valine. The absence of sulfur-containing amino acid could be due to their instability in the course of the experiment, although it is known that these are not very common amino acids in mushroom.

Table 4 divides the free amino acids into several classes on the basis of their taste characteristics as described by Mau et al. (1998a, 1998b, 1998c). Aspartic and glutamic acids are classified as monosodium glutamate-like (MSG-like) components that contribute to the most typical mushroom taste, MSG-like and sweetness components would mainly be responsible for the at-
Table 5. Content of $5^{\prime}$-nucleotides and vitamin $\mathrm{D}_{2}$ in the sawdust mushroom and $\log$ mushroom.

\begin{tabular}{|c|c|c|c|c|}
\hline \multirow{2}{*}{ Cultivation } & \multicolumn{2}{|c|}{ Content (mg/g, dry weight $)^{a)}$} & \multicolumn{2}{|c|}{ Content (IU/g, dry weight) ${ }^{a}$} \\
\hline & $5^{\prime}$-AMP & $5^{\prime}$-GMP & $5^{\prime}$-UMP & Vitamin $\mathrm{D}_{2}$ \\
\hline $\begin{array}{l}\text { Sawdust } \\
\text { mushroom }\end{array}$ & $0.35 \pm 0.02$ & $0.42 \pm 0.02$ & $0.53 \pm 0.02$ & $15.46 \pm 0.14$ \\
\hline $\begin{array}{l}\text { Log } \\
\text { mushroom }\end{array}$ & $0.25 \pm 0.02$ & $1.00 \pm 0.03$ & $0.86 \pm 0.03$ & $7.84 \pm 0.06$ \\
\hline
\end{tabular}

tractive taste of $G$. frondosa. Sweet tasting amino acids such as alanine were appreciably higher in the mushroom cultivated on logs than on sawdust substrate, while the bitter and tasteless amino acids valine, tyrosine, and histidine were low in total free amino acids in the mushroom cultivated on logs. The bitterness from bitter components in mushroom was probably masked by sweet components (Mau et al., 1998a). It is thought, therefore, that when the $G$. frondosa cultivated on logs were exposed to sun, the umami and sweet tasting amino acids increased, but bitter tasting ones decreased. Kiribuchi (1991) found that the free amino acids pertaining to umami and sweet taste in L. edodes, P. ostreatus and $F$. velutipes were increased by sun or ultraviolet light irradiation, but bitter tasting amino acids were decreased. These findings indicate that the log mushroom may taste better than sawdust mushroom.

Free amino acids in the fruit body were not related to protein content in the substrates. The total free amino acids in the mushroom cultivated on the two substrates were of the same degree in spite of there being less protein in the log substrate. These different behaviors of total amino acids and protein could be caused by the temperature and moisture of the medium, and the nutrient integration in the formation stage of the fruiting bodies. Komatsu and Tokimoto (1982) observed that the primordium formation of L. edodes was influenced by the temperature and moisture content of the bed-log. Moreover, Matsumoto and Kitamoto (1987) found that the exposure to light of the cultures in the mycelial growth stage is indispensable for the fruit body formation of $L$. edodes.

The content of $5^{\prime}$-nucleotides and vitamin $\mathrm{D}_{2}$ is shown in Table 5. Flavor 5'-GMP was significantly higher in the log mushroom than in sawdust mushroom. It is well known that $5^{\prime}$-nucleotides and MSG-like components greatly increases synergistically the umami or palatable taste (Yamaguchi et al., 1971; Yamaguchi, 1979).

The taste intensities (Ariyoshi, 1974) of sawdust and log mushroom are evaluated as 12 and 19, respectively, based on the mixture ratios of $5^{\prime}$-GMP to MSG-like components shown in Table 4 and Table 5.

The vitamin $\mathrm{D}_{2}$ content in sawdust mushroom was significantly higher than that in the log mushroom. Kiribuchi (1990a, $1990 b, 1992$ ) found that the amount of vitamin $\mathrm{D}_{2}$ in F. velutipes is significantly increased by sun light or ultraviolet irradiation. This fact contradicts our experimental result. However, Takeuchi and others (1985) reported that vitamin $\mathrm{D}_{2}$ in $G$. frondosa was produced without solar radiation. It is left for a future study to understand the reason why the mushroom cultivated in the sawdust substrate contains more vitamin $\mathrm{D}_{2}$.

Finally, according to the results of the taste components, we 
believe that $G$. frondosa mushroom cultivated on logs are tastier and more natural tasting than those cultivated on sawdust substrate. However, a further sensory evaluation is needed to confirm the findings of chemical compositions.

\section{References}

Aoyagi, Y., Kasuga, A., Sasaki, H., Matsuzawa, M., Tsutagawa, Y. and Kawai, H. (1993). Chemical compositions of Shiitake mushroom [Lentinus edodes (Berk.) Sing.] cultivated on logs and sawdust substrate beds and their relations to composition of the substrate. Nippon Shokuhin Kogyo Gakkaishi, 40, 771-775 (in Japanese).

Ariyoshi, Y. (1974). Taste and chemical structure (3). Kagaku to Seibutu, 12, 340-347 (in Japanese).

Fujihara, S., Kasuga, A., Aoyagi, Y. and Sugahara, T. (1995). Nitrogen-to-protein conversion factor for some common edible mushroom. J. Food Sci., 60, 1045-1047.

Imazeki, R. and Hongo, T. (1985). Colored Illustrations of Fungi of Japan II. Osaka: Hoikusha. p. 134 (in Japanese).

Kawai, H., Sugahara, T., Fujishiro, S., Matsuzawa, M., Aoyagi, Y. and Hosogai, Y. (1990). Mineral contents in edible mushroom growing on woods-Comparison with mineral contents in mushrooms growing in soil. Nippon Shokuhin Kogyo Gakkaishi, 37, 468-473 (in Japanese).

Kawai, H., Matsuzawa, M., Tsutagawa, Y., Sasaki, H., Kasuga, A. and Aoyagi, Y. (1994). Relationship between fruiting body compositions and substrate in Hiratake and Maitake mushrooms cultivated on sawdust substrate beds: Chemical compositions and mineral contents. Nippon Shokuhin Kogyo Gakkaishi, 41, 419-424 (in Japanese).

Kawazoe, T. and Yuasa, K. (1995). Efficient transformation of ergosterol to vitamin $\mathrm{D}_{2}$ by ultraviolet light irradiation. Nippon Shokuhin Kagaku Kogaku Kaishi, 42, 262-267 (in Japanese).

Kiribuchi, T. (1990a). Determination of ergosterol and vitamin $D_{2}$ in fungi. Kaseigaku Zasshi, 41, 395-400 (in Japanese).

Kiribuchi, T. (1990b). Study on vitamin $\mathrm{D}_{2}$ contents of various fungi by ultraviolet light irradiation. Kaseigaku Zasshi, 41, 401-406 (in Japanese).

Kiribuchi, T. (1991). Changes of free amino acid composition in fungi by sun or ultraviolet light irradiation. Kaseigaku Zasshi, 42, 415421 (in Japanese).

Kiribuchi, T. and Kawashima, K. (1992). Umami taste of Enokitake irradiated by ultraviolet light: Nucleotides in Enokitake. Kaseigaku Zasshi, 43, 1039-1042 (in Japanese).

Kiribuchi, T. (1992). Contents of vitamin $D_{2}$ in fungi irradiated by ultraviolet light under various conditions and changes in the contents during storage after irradiation. Kaseigaku Zasshi, 43, 649654 (in Japanese).

Komatsu, M. and Tokimoto, K. (1982). Effects of incubation temperature and moisture content of bed-logs on primordium formation of Lentinus edodes (Berk.) Sing. Rep. Tottori Mycol. Inst., 20, 104-112 (in Japanese).

Kubo, K., Aoki, H. and Nanba, H. (1994). Anti-diabetic activity present in the fruit body of Grifola frondosa (Maitake). J. Biol. Pharm. Bull., 17, 1106-1110.

Kubo, K. and Nanba, H. (1997). Anti-hyperliposis effect of Maitake fruit body (Grifola frondosa). J. Biol. Pharm. Bull., 20, 781-785.

Kurasawa, S., Sugahara, T. and Hayashi, J. (1982). Proximate and dietary fibre analysis of mushrooms. Nippon Shokuhin Kogyo Gakkaishi, 29, 400-406 (in Japanese).

Matsumoto, T. and Kitamoto, Y. (1987). Induction of fruit-body formation by water-flooding treatment in sawdust cultures of Lentinus edodes. Trans. Mycol. Soc. Jpn., 28, 437-443.

Mau, J.-L. and Tseng, Y.-H. (1998a). Nonvolatile taste components of three strains of Agrocybe cylindracea. J. Agric. Food Chem., 46, 2071-2074.

Mau, J.-L., Wu, K.-T., Wu, Y.-H. and Lin, Y.-P. (1998b). Nonvolatile taste components of ear mushrooms. J. Agric. Food Chem., 46 , $4583-4586$.

Mau, J.-L., Lin, Y.-P., Chen, P.-T., Wu, Y.-H. and Peng, J.-T. (1998c). Flavor compounds in king oyster mushrooms Pleurotus eryngii. J. Agric. Food Chem., 46, 4587-4591.

Muratsubaki, T., Sayama, K. and Sato, K. (1986). Change of constituents in fruit body formation of Grifola frondosa. Nippon Shokuhin Kogyo Gakkaishi, 33, 181-185 (in Japanese).

Ohashi, H. (2000). 2001 Mushroom Guide Book. Tokyo: Noson Bunkasya. p. 191 (in Japanese).

Ohnishi, M., Kawase, S., Kondo, Y., Fujino, Y. and Ito, S. (1996). Identification of major cerebroside species in seven edible mushrooms. Nihon Yukagakukaishi, 45, 51-56 (in Japanese).

Ohno, N., Suzuki, I., Sato, K., Oikawa, S., Miyazaki, T. and Yadomae, T. (1985). Purification and structural characterization of an antitumor $\beta$-1,3-glucan isolated from hot water extract of the fruit body of cultured Grifola frondosa. Chem. Pharm. Bull., 33, 4522-4527.

Ohtsuru, M., Horio, H., Masui, H. and Takeda, I. (1999). Bioactive substances in Grifola frondosa. Effects of administration of Grifola frondosa on blood and body weight in spontaneously hypertensive rats. Nippon Shokuhin Kagaku Kogaku Kaishi, 46, 806-814 (in Japanese).

Sasaki, H., Aoyagi, Y., Kasuga, A., Tanaka, Y., Matsuzawa, M. and Kawai, H. (1995). Relationships between fruit body compositions and substrates in Bunashimeji Hypsizigus marmoreus (Peck) Bigelow, Nameko [Pholiota nameko (T. Ito) S. Ito Imai in Imai], and Enokitake [Flammulina velutipes (Curt.: Fr.) Sing.] mushrooms cultivated on sawdust substrate beds. Nippon Shokuhin Kagaku Kogaku Kaishi, 42, 471-477 (in Japanese).

Sato, E., Aoyagi, Y. and Sugahara, T. (1985). Contents of free amino acids in mushrooms. Nippon Shokuhin Kogyo Gakkaishi, 32, 509521 (in Japanese).

Seguchi, M., Morimoto, N., Abe, M. and Yoshino, Y. (2001). Effect of Maitake (Grifola frondosa) mushroom powder on bread properties. J. Food Sci., 66, 261-264.

Sekizawa, N., Toyama, R. and Sekimura, T. (1992). Changes in 5'nucleotide content in edible mushrooms during processing. Nippon Shokuhin Kogyo Gakkaishi, 39, 72-78 (in Japanese).

Shindo, T., Ushiyama, H., Kan, K. and Yasuda, K. (1999). Study on content of cyanide in Basidiomycetes and the effect of cooking. Shokuhin Eiseigaku Zasshi, 40, 29-35 (in Japanese).

Sugahara, T. (1995). Shokuhingaku Jikkensho. Tokyo: Kenpakusha. pp. 43-71 (in Japanese).

Takeuchi, A., Okano, T., Torii, M., Hatanaka, Y. and Kobayashi, T. (1985). Identification and determination of vitamin $D_{2}$ in various fungi. Vitamins, 59, 195-201.

Yamaguchi, S., Yoshikawa, T., Ikeda, S. and Ninomiya, T. (1971). Measurement of the relative taste intensity of some $\mathrm{L}-\alpha$-amino acid and 5'-nucleotides. J. Food Sci., 36, 846-849.

Yamaguchi, S. (1979). The umami taste. "In Food Taste Chemistry", ed. by J.C. Boudreau. ACS Symposium Series. Washington, DC: American Chemical Society. pp. 33-51.

Yamasaki, Y. and Tabata, T. (2002). Comparison of the chemical and free amino acid composition of Nameko [Pholiota nameko (T. Ito)] cultivated on logs and in sawdust substrate beds. J. Home Econ. Jpn., 53, 1193-1196.

Yokokawa, Y. (1980). Fatty acid and sterol compositions in mushrooms of ten species of Polyporaceae. Part II. Phytochemistry, 19, 2615-2618.

Yoshida, H., Sasaki, H., Fujimoto, S. and Sugahara, T. (1996). The chemical components of the vegetative mycelia of Basidiomycetes. Nippon Shokuhin Kagaku Kogaku Kaishi, 43, 748-755 (in Japanese).

Zhuang, C., Mizuno, T., Ito, H., Shimura, K., Sumiya, T., Kawade, M. and Inamori, Y. (1994). Fractionation and antitumor activity of polysaccharides from Grifola frondosa mycelium. Biosci. Biotechnol. Biochem., 58, 185-188. 